\title{
Parenteral nutrition support: Beyond gut feeling? Quality control study of parenteral nutrition practices in a Tertiary Care Hospital
}

\author{
Nagarajan Ramakrishnan, Bhuvaneshwari Shankar ${ }^{1}$, Lakshmi Ranganathan, D. K. Daphnee ${ }^{1}$, \\ Adithya Bharadwaj, Ramesh Venkataraman
}

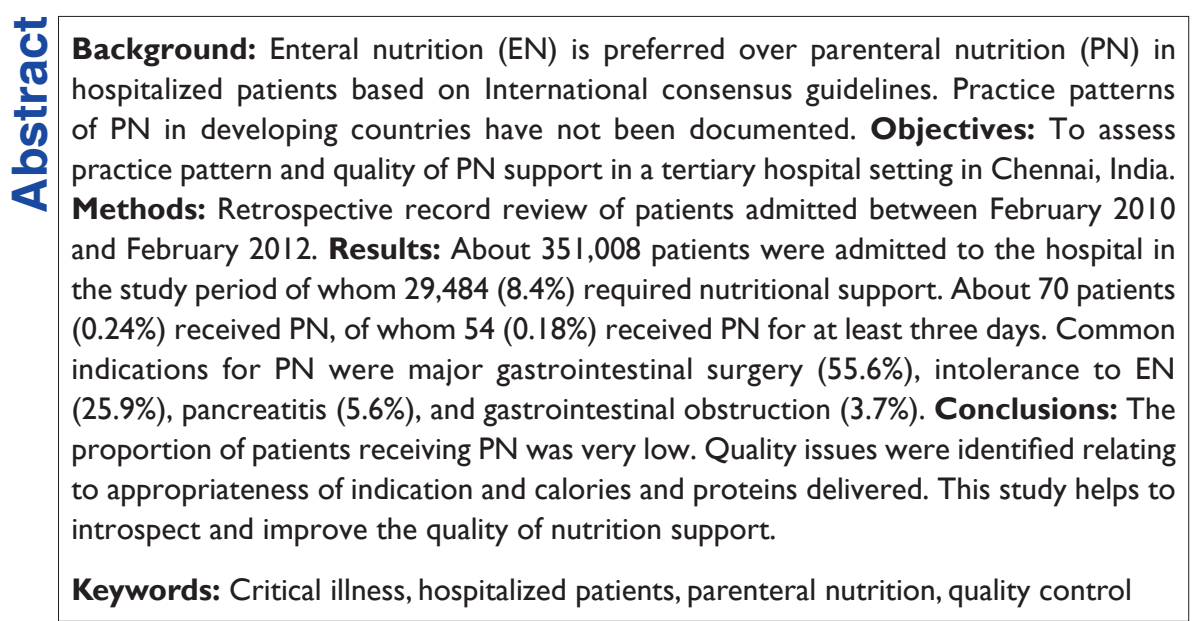

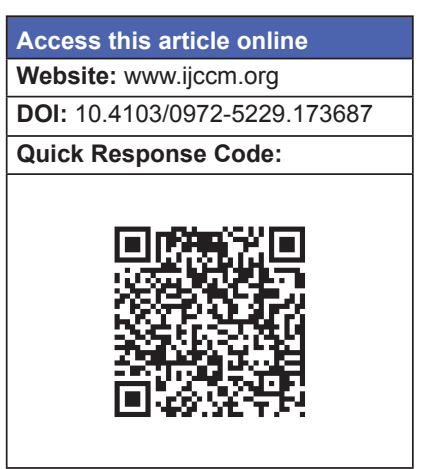

\section{Introduction}

Nutrition support for hospitalized patients has been a topic of great interest. Several advantages of enteral nutrition (EN) have been reported such as reduction in infection rates, the length of stay and mortality, all of which translate to a reduction in the cost of care. ${ }^{[1]}$ The American Society for Parenteral and EN and the European Society for Clinical Nutrition and Metabolism (ESPEN) currently recommend early initiation of EN for the critically ill patients and specific guidelines for the use of parenteral nutrition (PN). ${ }^{[2]}$ The 2009 European guidelines recommend that $\mathrm{PN}$ should be considered in "all patients who are not expected to be on EN within three days of Incentive Care Unit admission" or if EN is

From:

Departments of Critical Care, 'Dietetics, Apollo Hospitals, Chennai,

Tamil Nadu, India

\section{Correspondence:}

Dr. Nagarajan Ramakrishnan, Department of Critical Care Medicine, Apollo Hospitals, 21 Greams Lane, Chennai - 600 006, Tamil Nadu, India.

E-mail: icudoctor@gmail.com not feasible." ${ }^{[2]}$ Previous studies have demonstrated that quality of PN improves regarding calories and proteins delivered, infection rates, and quality of life of patients when appropriately administered by a nutritional support team. ${ }^{[3]}$ There is no available data on the practice and quality of PN delivery in the Indian setting. It is imperative that we audit this practice to optimize nutritional delivery and tailor PN only to appropriate patients. In this study, we aim to assess the prescription pattern and quality of nutritional delivery of PN support in a tertiary hospital setting in India.

This is an open access article distributed under the terms of the Creative Commons Attribution-NonCommercial-ShareAlike 3.0 License, which allows others to remix, tweak, and build upon the work non-commercially, as long as the author is credited and the new creations are licensed under the identical terms.

For reprints contact: reprints@ medknow.com

How to cite this article: Ramakrishnan N, Shankar B, Ranganathan L, Daphnee DK, Bharadwaj A, Venkataraman R. Parenteral nutrition support: Beyond gut feeling? Quality control study of parenteral nutrition practices in a Tertiary Care Hospital. Indian J Crit Care Med 2016;20:36-9. 


\section{Methods}

This study was done through a retrospective record review of all hospitalizations between February 2010 and February 2012. A checklist of items relevant to nutritional support was used to mine the data. PN support was defined as PN provided for at least 3 consecutive days of hospitalization. Data were validated by random supervisory checks and exported to a spreadsheet. All patient identifiers were masked and only relevant clinical information was extracted. The four components of the quality assessment framework followed in this study were proportion of nutrition provided as $\mathrm{PN}$, appropriateness of indication, process, and effectiveness of PN delivery [Figure 1]. Simple descriptive analysis was done to understand the pattern and profile of patients. Effectiveness of delivery of calorie and protein were analyzed using Student's $t$-test, and $P<0.05$ was considered significant. Statistical analyses were performed using SPSS statistical software (SPSS Statistics 17.0, Chicago, IL, USA). Since it was part of routine quality control process of the hospital, Ethical Committee approval was not sought.

\section{Results}

\section{Proportion of parenteral nutrition}

A total of 351,008 patients were admitted in the hospital during the study period. Of these, 29,484 (8.4\%) required supplemental nutritional support of whom only $70(0.24 \%)$ received some form of PN. About 54 $(0.18 \%)$ patients received PN for at least 3 consecutive days, $24(44.4 \%)$ of them received care in the coronary care unit (CCU), and $30(55.6 \%)$ in the ward.

\section{Appropriateness of parenteral nutrition}

The clinical profile of patients who received $\mathrm{PN}$ is shown in Table 1. Majority of the patients who received

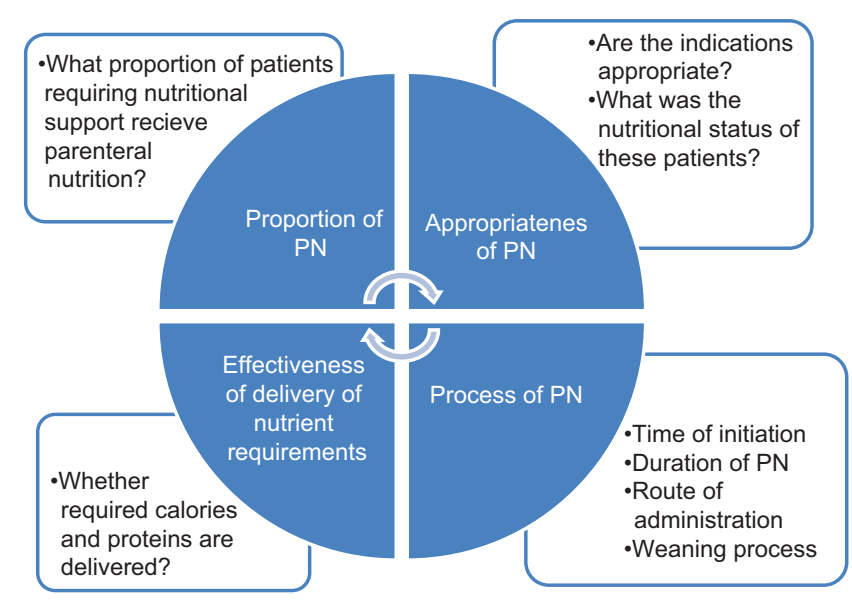

Figure I: Framework for quality assessment of parenteral nutrition
PN were moderately malnourished (63\%) at hospital admission based on the subjective global assessment tool. The most common indications for total parenteral nutrition (TPN) were major gastrointestinal surgery and intolerance to EN [Table 2].

PN was initiated within 5 days of hospitalization in $31(57.4 \%)$ of the patients, and the median duration was 6 days (interquartile range $3-19$ days). $P N$ was delivered as a commercially available premixed all-in-one bag admixture, which is currently the only option in India.

\section{Route of administration and process of weaning off parenteral nutrition}

The most common route of administration of PN was through a peripheral vein $(64.8 \%) .15$ patients $(25.9 \%)$ received it through a central line, and all of them were in the CCU [Figure 2]. Of the 54 patients who received PN, only 4 received total PN. 31 (57.4\%) of patients received simultaneous parenteral as well as EN support and 19 (33.3\%) received sequential oral or enteral supplementary nutritional support. In this cohort of patients, $30(55.5 \%)$ were started on an oral diet once the PN support was weaned off. Of these, 13 $(24 \%)$ were gradually weaned off to enteral feeding and the remaining 11 received both oral and enteral feeding following PN support.

\begin{tabular}{lc}
\hline \multicolumn{2}{l}{ Table I: Profile of patients who received parenteral nutrition } \\
\hline Characteristics & $\boldsymbol{n}(\%)$ \\
\hline Age (years) & $3(5.5)$ \\
$<30$ & $22(40.7)$ \\
$30-49$ & $20(37.0)$ \\
$50-69$ & $9(16.6)$ \\
$70-89$ & $54 \pm 14.8$ \\
Mean age (years) & $18(33.3)$ \\
Gender & $36(66.6)$ \\
Female & $60.87 \pm 16.6$ I \\
Male & $23.15 \pm 5.55$ \\
Mean weight (mean \pm SD) & \\
Mean BMI (mean \pm SD) & \\
Nutritional status on admission by & $19(35)$ \\
subjective global assessment tool & $34(63)$ \\
Well nourished & $1(2)$ \\
Moderately malnourished & \\
Severely malnourished &
\end{tabular}

Table 2: Indications for the use of parenteral nutrition

\begin{tabular}{lc}
\hline Indication for parenteral nutrition & Number of patients $\boldsymbol{n}(\%)$ \\
\hline Gastrointestinal surgery & $30(55.6)$ \\
Intolerance to enteral nutrition & $13(25.9)$ \\
Enterocutaneous fistula & $2(3.7)$ \\
Pancreatitis & $3(5.6)$ \\
Gastrointestinal obstruction & $2(3.7)$ \\
Malabsorption & $\mathrm{I}(1.8)$ \\
Others & $3(5.6)$ \\
\hline
\end{tabular}


Effectiveness of delivery of calorie and protein goals

The average calorie and protein requirements for the 54 patients who received PN support were $2018 \mathrm{Kcal}$ and $85 \mathrm{~g}$ proteins respectively. Only $907 \mathrm{Kcal}(45 \%)$ and $36.6 \mathrm{~g}$ proteins (43.5\%) were provided with an average volume of $1070 \mathrm{ml} /$ day [Table 3]. PN through central line provided significantly $(P=0.002)$ higher calories $(56 \%$ vs. $39.8 \%)$ and protein (49\% vs. $39.62 \%$ ) [Table 4]. However, there was no significant difference between CCU and wards in the effectiveness of delivery of calories and protein despite the higher use of central route in the CCU.

\section{Discussion}

This study describes the practice patterns of PN in a tertiary care setting in India. The most striking finding of this study was the very low rate of initiation $(0.24 \%)$ and continued use $(0.18 \%)$ of PN. Major gastrointestinal surgeries and intolerance to EN were the most common indications for PN. The predominant route of delivery was peripheral with a median duration of 6 days. Target

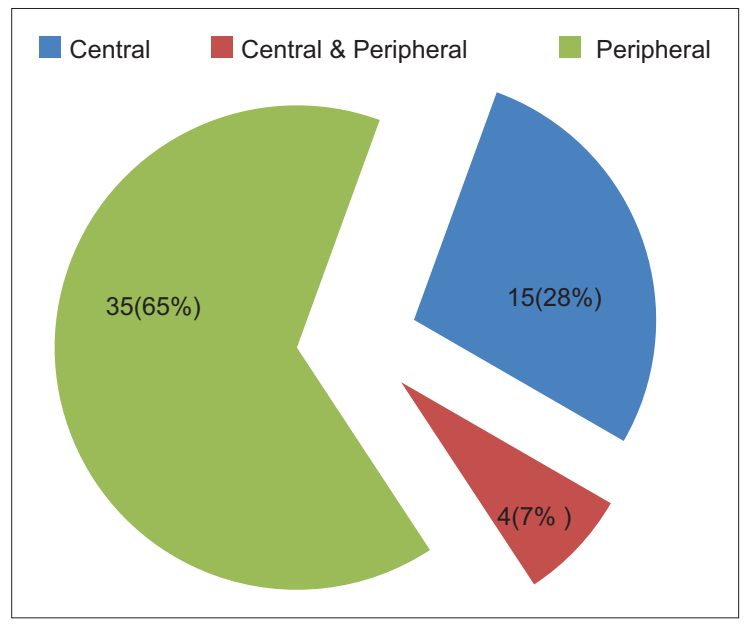

Figure 2: Route of administration of parenteral nutrition calories and proteins were unmet, and this may be due to limitations relating to volume restriction and use of premixed standardized solutions.

The low rate of PN in this tertiary care setting in India reveals a high awareness and practice consistent with evidence-based guidelines. However, it is important for these low rates of $\mathrm{PN}$ use in this hospital to be contextualized in the setting of practice patterns in other similar settings in India.

It was noted that gastrointestinal surgeries were the most common indication for PN use. It was common practice in the past to keep postoperative patients "nil by mouth" and maintain them on TPN. This concept is no longer recommended even in complicated gastrointestinal surgeries ${ }^{[4]}$ The higher rate of use of peripheral route and supplemental PN support may reflect the vestiges of the old practice and comfort level of surgeons. This should be addressed carefully in the light of emerging evidence. The current ESPEN guidelines for PN support clearly recommend the use of central venous lines for effective delivery ${ }^{[5]}$ Peripheral cannulas may be used when using fluids of low osmolarity ( $<850 \mathrm{mosm} / \mathrm{L})$ for a limited period of time when a substantial proportion of nonprotein calories is given as lipids. ${ }^{[5]}$ Our study reiterates prior knowledge that peripheral lines deliver nutrients with much lesser efficacy than the central lines. ${ }^{[5]}$ We noted that $\mathrm{PN}$ was used predominantly in the wards and in $<50 \%$ of patients in CCU. This may relate to the skill set of providers and logistic issues in care. Moreover, it was seen that about 50 patients received either simultaneous or sequential oral/ EN support when the volume of PN was substantially lower. The median duration of use ( 6 days) was not very high which could imply that several of these patients probably did not merit PN support. A small proportion

Table 3: Effectiveness of delivery of calorie and protein requirements through parenteral nutrition

\begin{tabular}{lccccccccc}
\hline & $\begin{array}{c}\text { Number } \\
\text { of patients }\end{array}$ & $\begin{array}{c}\text { Number } \\
\text { of days of } \\
\text { parenteral } \\
\text { nutrition }\end{array}$ & $\begin{array}{c}\text { Mean calorie } \\
\text { requirement }\end{array}$ & $\begin{array}{c}\text { Mean } \\
\text { calories } \\
\text { delivered }\end{array}$ & $\begin{array}{c}\text { Percentage } \\
\text { of calorie } \\
\text { requirement } \\
\text { delivered }\end{array}$ & $\begin{array}{c}\text { Mean protein } \\
\text { requirement }\end{array}$ & $\begin{array}{c}\text { Mean } \\
\text { proteins } \\
\text { delivered }\end{array}$ & $\begin{array}{c}\text { Percentage } \\
\text { of protein } \\
\text { requirement } \\
\text { delivered }\end{array}$ & $\begin{array}{c}\text { Mean volume } \\
\text { of parenteral } \\
\text { nutrition }\end{array}$ \\
\hline Total & 54 & $6.5(3-19)$ & 2018 & 907 & 45 & 85 & 36.6 & 43.5 & 1070 \\
Critical care unit & 24 & $6.75(3-18)$ & 2104 & 1021 & 48.5 & 92 & 42 & 45.6 & 1115 \\
Wards & 30 & $6.4(3-19)$ & 1948.9 & 815 & 41.8 & 79 & 32 & 40.5 & 1034 \\
\hline
\end{tabular}

\begin{tabular}{lcccccc}
\hline Table 4: Comparison of effectiveness of nutrient delivery through various routes of administration of parenteral nutrition \\
\hline Route & $\begin{array}{c}\text { Mean calories } \\
\text { requirement (Kcal) }\end{array}$ & $\begin{array}{c}\text { Mean calories } \\
\text { delivered (Kcal) }\end{array}$ & $\begin{array}{c}\text { Percentage of } \\
\text { calories delivered }\end{array}$ & $\begin{array}{c}\text { Mean proteins } \\
\text { requirement (g) }\end{array}$ & $\begin{array}{c}\text { Mean proteins } \\
\text { delivered (g) }\end{array}$ & $\begin{array}{c}\text { Percentage of } \\
\text { proteins delivered }\end{array}$ \\
\hline Central line & 2035 & $1 / 43$ & 56.16 & 95.9 & 47 & 49 \\
Peripheral line & 1990 & 792.35 & 39.81 & 79 & 31.3 & 39.62 \\
Central + peripheral line & 2193 & 1018 & 46.4 & 91.8 & 44 & 47.93 \\
\hline
\end{tabular}


of patients with pancreatitis were also maintained on PN support, which defies current knowledge from systemic reviews that demonstrate the benefit of EN compared to $\mathrm{PN}$ in this group. ${ }^{[1]}$

The poor delivery of required nutrition through PN in this study requires attention. As highlighted earlier, only premixed all-in-one bag admixtures are available in India and customized PN support is not an option. The practical limitations due to volume restrictions and the inherent limitations of premixed bags in delivering all nutrient requirements in the required proportion for a patient with multiple comorbidities are real and described earlier. ${ }^{[6]}$

A previous quality control audit from Switzerland showed that PN was appropriate in $93 \%$ of the patients. Overfeeding was observed in $62 \%$ against underfeeding in $14 \% .{ }^{[7]}$ Another audit from Northern England showed that $18 \%$ of patients on $\mathrm{PN}$ did not have a proper indication and $15 \%$ developed a complication. ${ }^{[8]}$ In another audit at the Medical University of South Carolina, $40 \%$ of the parenteral support was noted to be inappropriate and could have been avoided. ${ }^{[9]}$ In a tertiary care setting in Singapore, it was found that $15.9 \%$ of PN supports were inappropriate according to the ASPEN guidelines. ${ }^{[10]}$

This study is one of the very few documentations of PN practices in India. It is an important quality audit as it highlights the various aspects of PN therapy in the tertiary care setting and identifies gaps in nutritional support. The extremely low proportion of patients who received PN support in this hospital is in keeping with current evidence-based guidelines and could provide a reference for PN practice in other settings.

\section{Conclusion}

- Use of PN is very less in this tertiary hospital setting in keeping with emerging consensus

- The appropriateness of indications PN needs to be reviewed

- Use of peripheral venous line as the common route of administration needs to be reviewed and altered to align with current recommendations

- Delivery of required nutrition through PN is suboptimal.
This quality control study will help improving the quality of services and clinical outcomes. We would like to analyze our performance in implementing changes based on the findings and ensure quality assurance.

\section{Acknowledgments}

The authors acknowledge the support of Dr. Vijayaprasad G for data analysis and conceptual assistance in manuscript preparation.

\section{Financial support and sponsorship Nil.}

\section{Conflicts of interest}

There are no conflicts of interest.

\section{References}

1. Al-Omran M, Albalawi ZH, Tashkandi MF, Al-Ansary LA. Enteral versus parenteral nutrition for acute pancreatitis. Cochrane Database Syst Rev 2010;(1):CD002837.

2. McClave SA, Martindale RG, Vanek VW, McCarthy M, Roberts P, Taylor B, et al. Guidelines for the provision and assessment of nutrition support therapy in the adult critically Ill patient: Society of Critical Care Medicine (SCCM) and American Society for Parenteral and Enteral Nutrition (A.S.P.E.N.). JPEN J Parenter Enteral Nutr 2009;33:277-316.

3. Traeger SM, Williams GB, Milliren G, Young DS, Fisher M, Haug MT $3^{\text {rd }}$. Total parenteral nutrition by a nutrition support team: Improved quality of care. JPEN J Parenter Enteral Nutr 1986;10:408-12.

4. Yermilov I, Jain S, Sekeris E, Bentrem DJ, Hines OJ, Reber HA, et al. Utilization of parenteral nutrition following pancreaticoduodenectomy: Is routine jejunostomy tube placement warranted? Dig Dis Sci 2009;54:1582-8.

5. Pittiruti M, Hamilton H, Biffi R, MacFie J, Pertkiewicz M; ESPEN. ESPEN guidelines on parenteral nutrition: Central venous catheters (access, care, diagnosis and therapy of complications). Clin Nutr 2009;28:365-77.

6. Muhlebach S, Franken C, Stanga Z. Practical handling of AIO admixtures - Guidelines on Parenteral Nutrition, Chapter 10. Ger Med Sci 2009; $7: 1-8$.

7. Nardo P, Dupertuis YM, Jetzer J, Kossovsky MP, Darmon P, Pichard C. Clinical relevance of parenteral nutrition prescription and administration in 200 hospitalized patients: A quality control study. Clin Nutr 2008;27:858-64.

8. Hearnshaw SA, Thompson NP; Northern Nutrition Network. Use of parenteral nutrition in hospitals in the North of England. J Hum Nutr Diet 2007;20:14-23.

9. DeLegge MH, Basel MD, Bannister C, Budak AR. Parenteral nutrition (PN) use for adult hospitalized patients: A study of usage in a tertiary medical center. Nutr Clin Pract 2007;22:246-9.

10. Chan SL, Luman W. Appropriateness of the use of parenteral nutrition in a local tertiary-care hospital. Ann Acad Med Singapore 2004;33:494-8. 